4. Carney PA, Conry CM, Mitchell KB, et al. The importance of and the complexities associated with measuring continuity of care during resident training: possible solutions do exist. Fam Med. 2016;48(4):286-293.

5. Walker J, Payne B, Clemans-Taylor BL, Snyder ED. Continuity of care in resident outpatient clinics: A scoping review of the literature. $J$ Grad Med Educ. 2018;10(1):16-25.

6. Weir SS, Page C, Newton WP. Continuity and access in an academic family medicine center. Fam Med. 2016;48(2):100-107.

$\begin{array}{ll}\text { Proth American } & \text { From the North } \\ \text { PRIMARY CARE } & \text { American Primary Care }\end{array}$

Ann Fam Med 2018;16:274-275. https://doi.org/10.1370/afm.2252.

\section{FIRST INTERNATIONAL CONFERENCE ON PRACTICE FACILITATION: A SUCCESS!}

Over a decade ago, at the 2007 annual Practice-based Research Network (PBRN) meeting, Melinda M. Davis and Zsolt Nagykaldi first met while participating on a panel on responsibilities and training for practice facilitators (PFs). The profession of practice facilitation has grown substantially since, with support from the Agency for Healthcare Research and Quality (AHRQ), emergence of multiple practice facilitator training programs, and an increasing interest in translating evidence into practice through research and practice improvement initiatives. In recognition of the needs of the emerging professional community of PFs and the opportunity to advance the science and best practices of practice facilitation, members of the Coordinated Coalition of Networks (CoCoNet2), an AHRQ Center for Primary Care Practice-Based Research and Learning, secured grant funding with the support of the North American Primary Care Research Group (NAP$\mathrm{CRG}$ ) to host the first International Conference on Practice Facilitation (ICPF) on November 29-30, 2017 in Louisville, KY.

ICPF 2017 attracted over 120 attendees, including active PFs, PF managers, and other PF stakeholders. Attendees represented 68 organizations across 37 states and provinces with close to $10 \%$ Canadian participants The ICPF 2017 agenda addressed 4 themes: (1) Building a learning community, (2) Enhancing sustainability and management of practice facilitation programs, (3) Improving training and professional development, and (4) Building the science and best practices. Conference co-chairs Drs Davis and Nagykaldi welcomed participants and led them through plenaries, innovative session formats (eg, speed think-tanks, professional town hall), and networking opportunities intended to foster meaningful interaction and learning.
Day 1 activities focused on building relationships and a shared understanding of practice facilitation. William Hogg, MD delivered the first plenary on "The Past, Present and Future of Practice Facilitation: An International Perspective" describing various models of facilitation in the United States, United Kingdom, Australia, and Canada, evidence on effectiveness, and opportunities for future research. Small group discussions reflected on the plenary and personal experience to build a shared understanding of who PFs are, what they do and where, and how they are supported.

Next, a series of speed think-tanks co-facilitated by PFs and program leads addressed challenging and critical topics that ranged from "The Practice Facilitator's Role with Health Information Technology" to "Practice Recruitment, Engagement, and Retention," and "Moving Beyond the Clinic Walls: The Role of Practice Facilitators in Engaging Stakeholders." Happy hour and dine-around groups closed out the day's activities.

Day 2 began with breakfast roundtables and focused on variation in practice setting and on building a learning community for those engaged in practice facilitation. Three mini-plenaries provided an overview of PF programs in different environments including academic settings, a public health approach for success in payment reform, and health systems and payerbased programs. Key takeaways from small group discussions highlighted expansion of practice facilitation primarily from PBRN settings to programs housed in health systems, payers, and public health programs.

As part of the a' la carte series, national experts gave brief presentations on PF training and courses, successful regional programs, and methods to evaluate effectiveness. The second plenary by Michael Parchman, MD, MPH on "Strategies to Build a Professional Learning Community (PLC) for Practice Facilitation" was followed by a Town Hall hosted by Mindy Stadtlander, which engaged attendees in a lively discussion on building and sustaining a PLC. As one attendee commented, "I came away with a sense of community and felt inspired to try some creative new things." Areas of interest for the PLC included tailoring activities for different target audiences, creating a repository of tools and resources, clarifying skills and competencies, and refining criteria for training programs and skills development.

Six rapid learning workshops provided attendees with tools and resources on topics including program supervision, academic detailing, cognitive task analysis, value-based healthcare, evaluation, and patient/community engagement. The conference concluded with a discussion of key stakeholder groups through the 30-minute "Solution Shop: Do you have Questions? We Will Find Answers!" 
The ICPF is the result of the hard work and aspirations of researchers, health care professionals, and facilitators dedicated to the development and dissemination of practice facilitation. Evaluation comments reflecting high enthusiasm and engagement throughout include, "I thought the use of multiple types of learning opportunities was very innovative and fit the purpose of this first conference," "You did a great job fostering thoughtful and honest discussion, and "I enjoyed the interactive nature of the entire conference."

True to the spirit of facilitation, conference participants played a crucial role in determining the effectiveness of the conference by contributing their expertise with enthusiasm and honesty. Comments on the value of the conference highlighted opportunities for "Candid exchange among colleagues facing similar challenges," "Meeting so many other people in the field and hearing about the kind of work they are doing," and "The breakouts and table discussions made it easy to ask questions, have conversations, and learn from each other."

Videos of the plenary presentations are available on the NAPCRG website http://www.napcrg.org/Conferences/PastMeetingArchives/2017InternationalConferen ceonPracticeFacilitation.

The 2018 ICPF will take place in Tampa, Florida on December 10-11. The ICPF Steering Committee extends a warm invitation to all who are interested in practice facilitation! Registration is now open and abstracts are being accepting until July 20, 2018. http://www.napcrg.org/ICPF.

Melinda M. Davis, $P b D_{i}$ Zsolt Nagykaldi, $P b D_{i}$ Paula Darby Lipman, $P b D_{i}$ Jill Haugbt; On behalf of the ICPF Steering Committee

\section{Prom the American Academy}

Ann Fam Med 2018;16:275-276. https://doi.org/10.1370/afm.2258.

\section{QUICK APPROVAL REQUESTED FOR AAFP'S NEW PAYMENT MODEL}

After winning support from a panel of experts convened by Congress, the American Academy of Family Physicians (AAFP) has reminded the US Department of Health and Human Services (HHS) that testing for a new payment model created by the AAFP and tailored for primary care is only awaiting federal approval.

In a March 19 letter (https://www.aafp.org/ dam/AAFP/documents/advocacy/payment/apms/
LT-SecretaryAzar-APCAPM-031918.pdf) to HHS Secretary Alex Azar, the AAFP said the Advanced Primary Care Alternative Payment Model (APC-APM) (https:// www.aafp.org/content/dam/AAFP/documents/advocacy/payment/apms/PR-PTAC-APC-APM-41417.pdf) would help more than 200,000 primary care physicians promote coordinated care and provide incentives for practices to change the way patient care is delivered. The Academy urged Azar to approve the model quickly so testing can proceed.

"The APC-APM proposal is wholly consistent with the administration's goals of preserving independent medical practices, lowering the cost of health care, and reducing the administrative burden for physicians and other health care providers," the AAFP stated in the letter, which was signed by Board Chair John Meigs, MD, of Centreville, Alabama.

In December, the Physician-Focused Payment Model Technical Advisory Committee (PTAC), formed by Congress to review new Medicare payment models, recommended that HHS test the APC-APM on a limited scale. Six committee members voted for testing, 4 for implementation as a high priority and 1 for implementation - which, the AAFP pointed out, was just 1 vote shy of a recommendation to implement the model.

"In subsequent discussions, PTAC members, including those who voted for limited-scale testing, emphasized that the action on the model should be a high priority and undertaken urgently to support primary care and ensure robust access in all areas of the country," the letter stated.

PTAC members suggested that the APC-APM could be tested on a scale as large as or larger than that used for the Comprehensive Primary Care Plus (CPC+) model, and 1 member called the AAFP model superior to $\mathrm{CPC}+$

"As our nation grapples with the escalating costs of health care, we feel it is time to prioritize primary care, and wide-scale testing of the APC-APM is an important step toward achieving our mutual goals," the AAFP wrote to Azar.

Practices participating in the APC-APM would receive a monthly fee that covers face-to-face patient evaluation and management services. Separate monthly payments for population-based care would eliminate the need to bill for chronic care and transitional care management.

The traditional fee-for-service model asks primary care physicians to spend more time on administrative tasks without an increase in payment. The APC-APM, on the other hand, is designed to reduce administrative burden while supporting efforts to move into more advanced forms of patient care, and it includes both some risk and incentives for high performance. 